\title{
MUJERES DE ETA: LECTURA DE SUS REPRESENTACIONES EN EL DISCURSO
}

\author{
Ignacio Alberto Lozano Torres \\ naxolozanot@gmail.com \\ Universidad Autónoma de Madrid - España
}

Recibido: 09-11-2015

Aceptado: 18-05-2016

\section{Resumen}

El presente ensayo constituye un análisis detallado de las representaciones tradicionalmente atribuidas a las mujeres pertenecientes a ETA, tanto en el discurso dominante como en el propio discurso de la organización. Para dar base a dicho análisis, previamente se hará un repaso de las representaciones, simbología, imágenes y otras asunciones operantes en torno a la relación mujer-violencia y mujer-nacionalismo vasco. Una vez proporcionado el marco, se procederá a estudiar los mecanismos que la sociedad utiliza para encajar a estas mujeres en la lógica patriarcal imperante. Mediante entrevistas, testimonios y ciertas dosis de cultura abertzale, se deconstruirá la posición que la sociedad machista reserva a las activistas de ETA, culminando con el estudio de dos acontecimientos concretos seleccionados por su gran fuerza representativa: el asesinato de Dolores Katarain -Yoyes- y el funeral de Miren Bakartxo Arzelus.

Palabras Clave: ETA, representaciones, mujer, feminismo, violencia política, identidad.

\begin{abstract}
This essay constitutes a detailed analysis of the representations which are traditionally attributed to female members of ETA, those in the dominant discourse and those in the discourse of the organization itself. In order to provide a basis for such analysis, a review of the representations, symbology, images and other assumptions taking place in the relation woman-violence and woman-Basque nationalism will be previously made. Once the frame is given, we will study the mechanisms used by the society to fit these women in the prevailing patriarchal ideology. Looking at some interviews, testimonies and certain aspects of the abertzale culture, the position reserved to the female activists by the macho society will be deconstructed. To finish, we will develop a study of two concrete events chosen because of their huge representative strenght: the murder of Dolores Katarain -Yoyes- and the funeral of Miren Bakartxo Arzelus.
\end{abstract}

Keywords: ETA, representations, woman, feminism, political violence, identity. 


\section{Introducción}

Se comenzará por aclarar la ausencia de intención ofensiva del presente ensayo académico. Pero como ello no garantiza las consecuencias reales del mismo, se continuará por pedir disculpas por adelantado a quien pudiera sentirse ofendido. Es un tema altamente delicado y sería inconsciente pasar por alto sus controvertidas connotaciones morales.

El fin último de este estudio es llevar a cabo un análisis pormenorizado de la representación de la mujer que toma parte activa en la violencia con fines políticos, concretamente en la organización ETA -por ser la más visible para la sociedad española, durante los años en que se mantuvo en activo-, tanto en el discurso dominante como en el de la propia banda. Es necesario precisar que, a lo largo del texto, en ningún momento habrá referencias a ETA como "organización terrorista" (como así ocurre en la mayoría de las fuentes consultadas), puesto que dicha categorización supondría invisibilizar su carácter político y el contexto histórico en el que desarrolló su actividad, incluyendo la violencia ejercida por parte del estado español (Hamilton, 2007). No significa esto que no se reconozca el tremendo sufrimiento experimentado por las víctimas y sus allegados, blanco de brutales asesinatos, secuestros despiadados y demás acciones realizadas por esta organización. Significa tan sólo que, en este caso, colocaremos el foco sobre la otra parte del tablero.

En primer lugar, se abordarán los mecanismos que la sociedad pone en marcha para representar, justificar y "neutralizar" la violencia ejercida por las mujeres - entiéndase por "neutralizar" el hecho de ofrecer una explicación que tenga cabida en la concepción patriarcal del sistema de géneros que rige actualmente-. Se analizará, entre otros, la contribución de los medios de comunicación a la "deshumanización" de las mujeres autoras de acciones violentas y demás degeneraciones tradicionalmente atribuidas a las mismas (Agra Romero, 2012).

Seguidamente, se hará una inmersión en el desarrollo histórico del nacionalismo vasco, así como en sus fundamentos teóricos y sus efectos prácticos, con el objetivo de averiguar el papel y el espacio que concede a la mujer vasca $y$, de paso, qué tipo de relación mantiene con el feminismo. Se pretende con ello hallar una explicación, justificación o antecedente a la potente estructura patriarcal vertebradora de ETA y a la compleja situación que le queda a la mujer activista dentro de la misma.

Todo ello para poder desarrollar un análisis de las representaciones a las que está sujeta tanto por parte de un bando como de otro-, en base a entrevistas a miembros de la organización, testimonios, textos periodísticos, inmersiones en la idiosincrasia abertzale y la profundización en hechos portadores de un enorme significado que, a priori, podría pasar desapercibido: el funeral de Miren Bakartxo Arzelus, primera mujer perteneciente a ETA asesinada, y la muerte de Yoyes a manos de la propia organización ocho meses después, habiendo sido la primera mujer dirigente de la banda. 


\section{Violencia de las mujeres}

Se partirá de lo más básico: la violencia no es un valor, característica o facultad -llámese $x$ - que el sistema patriarcal y misógino en el que somos socializados adjudique a las mujeres; la violencia se asocia a la virilidad. La consecuencia de ello es que cada mujer que ejerce la violencia transgrede, lógicamente, el eje estructurador del mundo en el que actúa. Agra Romero (2012: 55), afirma: "la violencia de las mujeres cae fuera de las normas y compresiones idealtípicas de lo que significa ser mujer". Son actos que confrontan directamente la naturalización de la división por género a la que somos sometidos y sometidas desde el momento en que nacemos. ¿Cuál es la mejor manera de contrarrestarlos? Naturalizar también estas supuestas "excepciones" -si es que pueden considerarse tales, en un contexto en que las mujeres son educadas para ser sumisas y vulnerables-, aplicándoles un filtro que las transforme en meros elementos perpetuadores de la desigualdad en la que estamos inmersos. Existen diversos mecanismos para alcanzar este cometido, que serán descritos a continuación.

Varios de ellos resultan, en primera instancia, de un factor interesante: nuestro sentido de la humanidad. El experto estadounidense en seguridad internacional Robert A. Pape (2006), citado por Agra Romero (2012), expone la tesis de que es mucho más cómodo y asimilable para nuestro cerebro humano "contaminado" por el elemento socialización, atribuir actos "inhumanos" a seres "inhumanos". No se puede afirmar que sea éste un factor que afecte únicamente a las mujeres; los hombres también son objeto del mismo -cuando pensamos en crímenes terribles para la historia de la humanidad acuñados por varones, por ejemplo los atentados del 11-S, en nuestras cabezas se producen asociaciones que contribuyen a la construcción de representaciones de los autores como auténticas bestias sedientas de sangre y cegadas por el odio, saboreando cada segundo de sus atrocidades y alimentándose con el terror de sus víctimas-. El problema en cuestión es que dichas asociaciones son activadas por el sistema de valores que la sociedad nos ha llevado a interiorizar (el sistema sexo/género será nuestro punto de referencia en este caso), de manera que lo se produce no es más que una mera reproducción de los estereotipos de género, pero en un plano distinto al que estamos acostumbrados - lo que muy probablemente contribuya al hecho de pasarlo por alto.

Así, las representaciones mentales que maneja la sociedad tienden a vincular, una vez más incluso en este plano, la virilidad con la razón y la feminidad con la emoción. A efectos prácticos, con respecto al tema que nos ocupa, esto significa que a los hombres se les reconoce la lucha política, mientras que a las mujeres no (Agra Romero, 2012). Será sencillo concebir las motivaciones políticas de un islamista radical, a pesar de que se condenen vehementemente, pero será extraordinariamente difícil suponer a una activista de ETA el carácter político de sus actos, revistiendo los mismos con preconcepciones femeninas que llevarán a concluir que su verdadero móvil es la venganza personal, un enamoramiento apasionado o cualquier otra degeneración de sus impulsos. 
Popularmente, persiste la creencia de que las mujeres son mucho más crueles y perversas que los hombres, imagen reforzada por los medios de comunicación con la hipervisibilización de la violencia perpetrada por ellas - contrapuesta a la invisibilización de la violencia que sufren, infinitamente más frecuente (Agra Romero, 2012) -. Se las presenta como seres que padecen una degeneración de su sexualidad: o bien se las hipersexualiza y se las convierte en auténticas femmes fatales, sedientas de sangre para satisfacer sus deseos -bellas, calculadoras y frías-; o bien como lesbianas feministas enloquecidas, cegadas por su odio hacia el macho; o bien simplemente como personas demasiado feas que matan simplemente para obtener esa atención que nunca han logrado captar con su físico. Se incide constantemente en una supuesta anti-naturalidad que busca regocijarse en "la idea de que no son mujeres «como deben ser»" (Agra Romero, 2012: 60). Son monstruos, en palabras de la escritora Eileen Macdonald (1992), citado por Agra Romero (2012: 60), culpables de un doble crimen: "usar la violencia y al hacerlo, destruir nuestra visión tradicional y segura de las mujeres"1.

No obstante, hay ocasiones en que ni siquiera es necesario llegar al extremo de "caricaturizar" a estas mujeres como seres anti-naturales. Muchas veces, sus actos encajan en el molde social impuesto; simplemente, ellas han querido ir un poco más allá -si es que la forma verbal "han querido" no les otorga una agencia que, por supuesto, a estos seres tan indefensos e influenciables no les corresponde-. "Su violencia política no se considera impulsada por la ideología o la creencia en una causa, sino como «una perversión del ámbito privado», es decir, en relación con el papel de madre o esposa” (Agra Romero, 2012: 61).

Como resultado se obtienen falacias, presentadas incluso como argumentos feministas, que niegan la capacidad de la mujer para unirse voluntaria e independientemente a la lucha política a través de las armas, atribuyendo la responsabilidad de su presencia en bandas armadas a algún hombre con el que mantienen un lazo afectivo. Es, según la feminista radical americana Robin Morgan (1988), citado por Hamilton (2007), lo que se denomina couple terrorism [terrorismo en pareja]. Incluso el politólogo español, experto en terrorismo, Fernando Reinares -quien realizó una serie de entrevistas a miembros de ETA entre las décadas de los 70 y los 90-, a pesar de hallar evidencias de compromiso político personal por parte de las activistas femeninas, previo a su ingreso en la banda, concluye que el factor determinante a la hora de acceder a la misma es la vinculación emocional con alguno de sus miembros ${ }^{2}$ (Hamilton, 2007). Otra manera de negar la capacidad de agencia de las mujeres perpetuando los estereotipos de género.

Y también pueden justificarse sus baños de sangre otorgando al asunto cierto carácter biológico: recurriendo una vez más a la maternidad para definir a la mujer. Podemos explicar su presencia en actividades de infraestructura de organizaciones armadas mediante su instinto maternal; es la lógica de la inmolación la que, como si fuera una obligación de madre, la lleva a

\footnotetext{
${ }^{1}$ Afirmación contenida en su libro "Shoot the Women First" (1992), fruto de una investigación donde intenta deconstruir la imagen monstruosa de las mujeres terroristas.

${ }^{2}$ Análisis realizado en su obra "Patriotas de la muerte" (2001).
} 
ocuparse de la labor del ámbito privado de la banda. O podemos encajar sus crímenes contra la humanidad, culpando a la frustración que experimenta al sentir que ha fracasado como mujer por el hecho de no poder traer hijos al mundo o no poder casarse (Agra Romero, 2012).

Definitivamente, la verdadera cuestión es:

"Por qué hay que explicar la violencia de las mujeres por su incapacidad de dar a luz o por categorías, digamos, de filiación (esposas, madres, hijas, hermanas) y no de afiliación, por qué referirla a motivos o explicarla en términos, personales y no políticos" (Agra Romero, 2012: 62).

\section{EI nacionalismo vasco y las mujeres}

Antes que nada, de un modo general, se prestará atención al concepto de ciudadanía. Resulta evidente que los derechos que se desprenden de la ciudadanía que gozan los hombres no son los mismos que ostentan las mujeres. Las mujeres juegan en una categoría inferior en su estatus de miembros conformadores de los estados-nación; y es que no son concebidas como individuos semejantes a los varones, sino como parte integrante e irremediable -más que necesaria- de una estructura familiar, pilar básico de la nación. La socióloga italiana Chiara Saraceno (1988), citado por Hernández García (1997), habla de una "ciudadanía subordinada"3, propuesta que, aparentemente, choca con el importante papel que la mayoría de los nacionalismos reservan a sus mujeres.

La identidad nacionalista vasca se construye, como tantas otras, a partir de una identificación común como raza única y, por qué no decirlo, superior de alguna manera -el desarrollo de todas las sociedades humanas implica cierto sentimiento de trascendencia respecto a la inmanencia que constituye el resto-. Sabino Arana, considerado padre del nacionalismo vasco, cataloga a la mujer como "baluarte y salvaguarda de la pureza de la raza" (Hernández García, 1997: 23), rol que porta implicaciones nefastas para las vascas. Se retorna a la naturalización de la que hablábamos al principio: se utilizan tintes biologicistas para revestir de racionalidad y necesariedad el confinamiento de las mujeres dentro del binomio mujer-madre (Hernández García, 1997). De manera que ya tenemos excusa para dirigir, limitar, impedir o promover cualquier aspecto de sus vidas.

El efecto más inmediato de convertirlas en responsables de la "pureza de la raza", es el control ejercido sobre sus cuerpos y su sexualidad. El siguiente, su reclusión en el ámbito privado o doméstico, que vascos y vascas tienen muy bien interiorizado gracias al concepto Etxekoandre [mujer de la casa] y reforzado por el prominente papel de las madres en el entorno

\footnotetext{
${ }^{3}$ Concepto desarrollado en su artículo "La estructura del género de la ciudadanía” (1988).
} 
rural vasco -constituyen una figura central en el baserri [propiedad rural]. (Hernández García, 1997)

En consecuencia, su participación en la esfera del nacionalismo vasco se reduce a un pequeño porcentaje de representación en la política formal, que se va reduciendo de manera proporcional al aumento de la complejidad de la misma. Y fuera de la política, se limitan a realizar labores de infraestructura, a medio camino entre lo social y lo político, en lo que se considera un plano de "apoyo o afectivo" (Hernández García, 1997: 24). Es decir, participan en el ámbito público de una forma que no hace sino perpetuar los roles donde se encuentran contenidas. ¿De dónde estriba esta imposibilidad para auto-reivindicarse como agentes de cambio?

"El contexto nacionalista continúa salpicado de elementos de tradición y escollos inmovilistas que impiden la participación plena de las mujeres en esferas relevantes del universo cultural vasco, y que por lo tanto niegan el cambio y el desarrollo de nuevos modelos de participación” (Hernández García, 1997: 25).

\subsection{Nacionalismo y feminismo vascos}

Centrémonos ahora, en las mujeres que han tenido la oportunidad de empoderarse lo suficiente como para convertirse en promotoras de un auténtico cambio estructural en la sociedad machista vasca. Trabajaremos en torno a un concepto acuñado por Carrie Hamilton (2007): "nationalist feminism [feminismo nacionalista]", en oposición al que opera normalmente -“feminist nationalism [nacionalismo feminista]"-puesto que ayuda a la visibilización de la aspiración prioritaria hacia una sociedad igualitaria, que incorpora el nacionalismo en su agenda política (Hamilton, 2007).

En España, la dictadura franquista provocó el retraso de la llegada del feminismo de la segunda ola hasta mediados de la década de los 70. Las feministas de entonces debían enfrentar una situación peculiar: compaginar su activismo feminista con la militancia en partidos políticos de corte claramente patriarcal. Esto llevó al consentimiento de que asuntos "más relevantes" pasaran por encima de sus exigencias por la igualdad. Finalmente, sus propuestas y sus voces fueron silenciadas, haciéndolas caer en un sentimiento de frustración que trajo consigo la fragmentación de la fuerza feminista en España. (Hamilton, 2007)

Sin embargo, se podría decir que el País Vasco constituye la excepción que confirma la regla: "the struggle over the Basque Autonomy Statute and the escalation of popular mobilisation, political violence, and police repression, provided a markedly different environment for the development of the Basque women' movement" ${ }^{\prime 4}$ (Hamilton, 2007: 150).

\footnotetext{
4 "La lucha por el Estatuto de Autonomía vasco y la escalada de movilizaciones populares, violencia política, y represión policial, proporcionaron un contexto diferente para la movilización de las mujeres vascas" (la traducción es nuestra).
} 
Así, las feministas vascas se organizaron en asambleas provinciales de mujeres, otorgando el marco institucional al movimiento feminista que quizás faltó en el resto de España. Asambleas que no se definían como nacionalistas, pero que incorporaban en sus agendas ciertas demandas con respecto al conflicto vasco.

Por otra parte, el primer intento de crear una organización feminista dentro del contexto del nacionalismo radical se materializa con el nacimiento de $K A S^{5}$ Emakumeak [KAS mujeres], en 1978. Se trataba de una organización de mujeres nacionalistas que hizo lo posible por reproducir, en el entorno vasco, los esfuerzos del feminismo de la segunda ola para encarar la naturaleza de las interacciones entre género, clase social y grupo étnico. En consonancia con su idiosincrasia anti-patriarcal, contraria al capitalismo y al imperialismo español, consagraron su labor a la triple discriminación que suponía ser mujer, trabajadora y vasca. Posteriormente, en 1981, tras su disolución, le sucedería la organización Aizan. Por desgracia, su situación era frustrante debido a la ausencia de reconocimiento: la coalición $K A S$, como coordinadora de las organizaciones inscritas en el nacionalismo radical vasco, jamás le otorgó a ninguna de las dos la legitimidad para alcanzar el estatus del resto de agrupaciones.

En esa coalición, encarnaba un papel especialmente referencial la organización ETA $(\mathrm{m})^{6}$; infundía un peculiar respeto en el resto de agrupaciones, que la percibían como verdadero baluarte del nacionalismo vasco. Sobre el papel, ETA (m) apoyaba el movimiento de liberación de la mujer e incluía el feminismo entre los movimientos sociales a los que prestaba su apoyo (Hamilton, 2007). En la práctica, se debe tener en mente que ETA fue una organización fundada en el año 1959 exclusivamente por hombres ("La dictadura del terror", 2009) y que la incorporación de mujeres a la misma fue muy reducida hasta la década de los 80 (Hamilton, 2007) -aun así, no se pretende insinuar en ningún caso que su incorporación, su participación en acciones violentas o su acceso a puestos de mando impliquen una asimilación de su estatus en la banda con el de los hombres-. ETA no deja de ser una institución absolutamente patriarcal reproductora de los convencionalismos sociales vertebradores de la sociedad vasca, a la que pretende liberar de la opresión del estado español. Por su carácter marxista y leninista ("La dictadura del terror”, 2009), aspira a suprimir el yugo capitalista explotador que le viene impuesto desde Madrid y asfixia al trabajador vasco. Una vez más, como tantas veces a lo largo de la historia, parece que nos hemos vuelto a olvidar de las cadenas que el estado español, el capitalismo, el marxismo, el leninismo y la sociedad vasca colocan alrededor de la mujer; $¿ \mathrm{a}$ ella no hay que liberarla?

No obstante, también hay que recordar que hubo un período de "comunión" entre las agrupaciones feministas vascas y las organizaciones nacionalistas radicales gracias a dos

\footnotetext{
${ }^{5}$ Koordinadora Abertzale Sozialista [Coordinadora Patriota Socialista]: organización colectiva que aglutinaba todas las agrupaciones que habían surgido afines a la izquierda abertzale; por ejemplo, ETA (pm), ETA (m) o HB formaban parte de ésta.

${ }^{6}$ En 1974 la banda armada ETA se escinde, dando lugar a ETA (m) [ETA militar], partidarios de la violencia indiscriminada, y ETA (pm) [ETA político-militar], partidarios de la violencia selectiva.
} 
acontecimientos fundamentales para el feminismo vasco: el juicio de Basauri (1979-1982) a once mujeres detenidas por prácticas abortistas, y una serie de agresiones sexuales que tuvieron lugar al año siguiente (1980) y que sufrieron jóvenes relacionadas con el movimiento nacionalista vasco (Hamilton, 2007). La sociedad vasca por completo mostró su solidaridad con las víctimas en ambos casos $\mathrm{y}$, en concreto, los grupos nacionalistas radicales actuaron en consecuencia -ETA (m) actuó contra la propiedad de un prominente doctor anti-abortista para protestar contra el juicio a las abortistas, y ETA (pm) llevó a cabo una acción armada en Bilbao contra unos cines en los que se proyectaba pornografía, como respuesta a las agresiones sexuales.

El problema es que también se desprende cierto tufillo patriarcal de esta supuesta solidaridad con las mujeres vascas. El juicio de Basauri fue percibido más como un problema de clase social que como un caso de violencia sobre las mujeres perpetuadora del control sobre sus cuerpos, y las agresiones sexuales se condenaron tan vehementemente no por el tipo de agresión que constituían -un auténtico atentado que enarbola una subordinación repugnante del género femenino hacia el masculino- sino por la identidad política de las víctimas, negando implícitamente el carácter político de toda violación. (Hamilton, 2007).

\section{Mujeres de ETA: representación en los discursos}

"I argue that women's ETA activism is an example of rebellion as agency. And precisely because it represented both a site of male privilege and a direct challenge to the authority of the Spanish state, ETA provided a particular appealing site for revolt against social norms"7 (Hamilton, 2007: 116).

El presente apartado se destinará a proporcionar un contexto a las palabras anteriores, presentar una base histórica, social y antropológica sobre la que puedan descansar y, sobretodo, desmontar todos los mitos y falsas representaciones que circulan en torno al tema referido ciñéndonos al discurso de la sociedad española, así como al del propio entorno abertzale-. El objetivo principal será demostrar la existencia de una conciencia política que justifique la participación de las mujeres en la organización, aunque resulte incluso indigno que las razones de su afiliación se planteen en otros términos.

\footnotetext{
7 "Mantengo que el activismo de las mujeres de ETA es un ejemplo de rebelión como voluntad de acción individualista. Y precisamente porque representa un espacio de privilegio masculino, así como un desafío directo a la autoridad del estado español, ETA se erigió en un espacio particularmente atractivo para la revuelta contra las normas sociales" (la traducción es nuestra).
} 


\subsection{Representaciones de las mujeres de ETA en el discurso dominante}

Al comienzo de la incorporación de las mujeres a la banda, coincidiendo con los últimos coletazos del franquismo y los años de la transición, los estereotipos de género tenían un peso social tan grande que la mayoría de las etarras detenidas obtenían sentencias mucho más livianas que sus compañeros o incluso eran absueltas (Hamilton, 2007). Se las creía incapaces de perpetrar cualquier tipo de violencia de forma autónoma y premeditada. Obviamente, la organización era consciente y jugaba con la baza a su favor de que resultaban menos sospechosas -quizás el couple terrorism ${ }^{8}$ del que hablaba Morgan no era más que una estrategia en lugar de una prueba de los lazos que unen a la mujer a la banda.

En la década de los 80, a medida que las activistas femeninas van haciéndose más visibles, se produce un giro en dicha representación: pasan a ser frías, calculadoras, más peligrosas incluso que sus homólogos masculinos. Así se refleja en estas palabras de la periodista Charo Zarzalejo 9 (Cambio 16, 13-12-1982: 30): "Pero la desazón de las reclusas «comunes» se convierte en el departamento de internadas políticas en un estado de ánimo más sereno, sin alegrías estridentes, pero lejos de ese clima humano sombrío de las «otras»". Palabras que dan a entender que no son mujeres normales, insinuando incluso que no son siquiera humanas. Curiosamente, los medios tampoco pueden esconder cierto grado de fascinación y misticismo ante esta nueva concepción sobre las mujeres que tienen la iniciativa de tomar las armas: en una entrevista a cinco activistas para la revista Cambio 16, se dice de una de ellas que es "alta, guapísima, un torbellino de energía y convicciones", de otra que "tiene un aire de Lizza Minelli" (Cambio 16, 13-12-1982: 30), y todo ello junto a una fotografía que deja ver la silueta de una mujer empuñando un rifle con aire solitario y reflexivo.

De ahí en adelante, a pesar de que ya bastantes eran identificadas como autoras de algunas de las acciones más sanguinarias o, incluso, como miembros de la cúpula de la organización, no se puede afirmar que los convencionalismos sociales en cuanto a su condición de mujeres perpetradoras de violencia hayan evolucionado.

Por un lado, se elucubra con una feminidad híper-sexualizada, se las representa como femmes fatales sedientas de sangre y poder, envueltas en un más que evidente halo de fatídica sensualidad. Por ejemplo, a Idoia López Riaño se le da el sobrenombre de "la Tigresa" -ha de decirse que tanto dentro como fuera de la banda-, lo cual deja entrever bastante el panorama, y de ella el periodista Matías Antolín (2004), supuesto experto en ETA, ha escrito cosas como: "Es indomable como una orquídea de acero inoxidable" (p. 19), "Se movía entre los hombres como una pantera, se escurría sigilosa entre los policías como una serpiente venenosa, se enredaba como una araña de ojos azules" (Antolín, 2004: 19), "Una de sus obsesiones era

\footnotetext{
${ }^{8}$ Referido en el apartado "La violencia de las mujeres" (p. 5).

9 Autora de un artículo ("Hablan las mujeres de ETA", publicado en la revista Cambio 16) en el que se entrevista a cinco militantes femeninas de ETA en el penal de Yeserías. Las jóvenes dan su parecer sobre el conflicto vasco y explican cómo se produjo su ingreso en la banda, así como los motivos de su entrada en prisión.
} 
seducir a los txakurras (perro, se usa contra los guardias civiles destinados en Euskadi)" (Antolín, 2004: 20) o "pero sus ojos, espectaculares, los realzaba con unos atractivos y voluminosos peinados y una vestimenta provocadora y acorde con su físico, muy sensual" (Antolín, 2004: 20). Se observa incluso que aumentan las dosis de misticismo, parece que se está hablando de un ser de leyenda.

Puede darse igualmente el caso contrario: se puede jugar a hiperbolizar los rasgos andróginos de las etarras e insinuar que son poco menos que monstruos más viriles que el macho ibérico con más testosterona de la comarca. Es la técnica que elegió usar el periodista José María Calleja (2001), citado por Hamilton (2007), a la hora de hablar de la muerte de Ina Zeberio a manos de la ertzaina:

"The etarra [member of ETA] looks like a brute, [with] wide shoulders, and the ertzainas who take part in the entry of the house where the etarra is hiding are sure, after suitably frisking her, that they're standing beside a man ... [they] verify that an abundant mop of black hair is coming out of the ETA member's chest" ${ }^{10}$.

En cualquier caso, lo que pretenden sugerir estas dos representaciones de manera subrepticia es que las mujeres que deciden unirse a la banda armada lo hacen como consecuencia de un trastorno en su sexualidad. Constituyen más bien una especie de advertencia: alertan de lo que puede ocurrir si se deja de controlar el cuerpo y la sexualidad de las mujeres.

$\mathrm{O}$, aunque parezca mentira, se puede retornar a la idea de que las activistas no están ahí por voluntad propia, evidentemente porque no tienen la capacidad, si no que sus impulsos propios de seres híper-emocionales las han conducido hasta esa posición, donde necesitan la protección y las directrices que solo un hombre puede proporcionar. Volveremos a fijarnos en las palabras de Antolín (2004: 32), en esta ocasión sobre Belén González Peñalba: "La verdad es que esta feroz asesina era bastante inútil para el manejo de las armas. Le temblaban las piernas ante la más mínima adversidad, se caía al suelo en los momentos de mayor exigencia (...)" o "No me cabe en la cabeza [...] que una mujer tan simple haya participado como interlocutora de la organización en las dos conversaciones más importantes que ha habido entre el gobierno español y ETA.” (Antolín, 2004: 36),

$\mathrm{Al}$ margen de lo anterior, y a modo de pequeña conclusión, podría decirse que el papel de las mujeres fue especialmente útil para la banda. Haciendo una analogía con las representaciones tradicionales de los etarras masculinos, ataviados con pasamontañas para ocultar su identidad -amenazantes por el hecho de no saber quién es el enemigo-, podría

\footnotetext{
10 "La etarra parece un salvaje, hombros anchos, y los ertzainas que toman parte en el asalto a la casa donde la etarra se esconde están seguros, después de un registro completo, de que se encuentran frente a un hombre ... verifican que una abundante mata de pelo oscuro asoma por el pecho de la miembro de ETA" (la traducción es nuestra).
} 
decirse que las activistas ya portan su propio pasamontañas por el hecho de ser mujer. Tras su identidad femenina esconden al verdadero etarra -incompatible a ojos de la sociedad con un cuerpo, una mente y una personalidad femenina- lo que las convierte en doblemente peligrosas (Hamilton, 2007). Desgraciadamente, en el común de la sociedad, estos prejuicios no hacen sino reforzar los estereotipos de género y negar la capacidad de agencia de las mujeres.

\subsubsection{Representaciones en torno a la incorporación de la mujer a la banda}

Consecuencia de estas representaciones, en lo que se refiere a la incorporación de la mujer a la organización, es la asunción existente en el imaginario colectivo de que las razones que dan pie a la misma son privadas o personales: son acusadas, o bien de falta de agencia -son arrastradas a la banda por un varón-, o bien de ser seres egoístas excesivamente independientes con una sexualidad deformada. Hamilton (2007: 111) niega, de acuerdo a sus investigaciones, cualquier tipo de pasividad, e intenta colocar el foco sobre una supuesta tensión entre las motivaciones personales y colectivas que llevan a las mujeres al ejercicio de la violencia con fines políticos:

"Evidence from ETA and other illegal armed organisations indicates that female activists enter armed movements for a variety of reasons, political and personal, which overlap substantially with men's motivations. Moreover, in the Basque and other cases, many female activists roundly deny that they were coerced or even encouraged to join by male partners. [...] women formerly active in ETA whom I interviewed stress instead their political and personal commitment to radical nationalism ${ }^{, 11}$.

Quisiera matizar la afirmación de que las motivaciones de las mujeres se asimilan en gran medida a las de los hombres; no pueden compararse las causas que mueven a unas y otros a la integración en la banda armada. A nivel colectivo, la lógica de la inmolación o sacrificio en la que son socializadas las mujeres -las de ETA y todas las del mundo- es causante de que se instaure en su mentalidad la creencia de que están obligadas a hacer algo por su pueblo, se erigen en responsables naturales del bien común. De manera que perciben su labor como "algo que toca" y, lejos de atribuirse cualquier tipo de mérito personal, se presentan a ellas mismas la mayoría de las ocasiones inscritas en una colectividad, como parte integrante de un pueblo al que deben su lucha: "Empecé de muy jovencita, en grupos juveniles", "Veía que el pueblo estaba oprimido, masacrado [...]", "Soñaba con entrar a la organización armada y además de

\footnotetext{
11 "Las pruebas que se recogen de ETA y otras organizaciones ilegales armadas indican que las activistas femeninas ingresan en movimientos armados por un conjunto de razones, políticas y personales, que se superponen sustancialmente con las motivaciones de los hombres. Además, en el caso vasco así como en otros, muchas activistas femeninas niegan rotundamente que fueran forzadas o incluso animadas a unirse por compañeros masculinos. [...] las antiguas activistas de ETA que he entrevistado ponen énfasis, en cambio, en su compromiso personal y político con el nacionalismo radical" (la traducción es nuestra).
} 
ser miembro de un comando." o "No soy una militante, pertenezco a la infraestructura" (Cambio 16, 13-12-1982: 31). En el discurso masculino, en cambio, el sujeto concibe su papel en la banda como una elección voluntaria y, debido a ese libre sacrificio realizado para salvar a su pueblo, se permite ciertas licencias y percibe con más facilidad la "heroicidad" de sus actos. Las razones de su acceso a la organización tienen un carácter más individualista.

A pesar de todo, no quisiera invisibilizar el carácter individualista impreso en la elección de las mujeres de pertenecer a ETA. En su militancia queda reflejada su rebelión contra las imposiciones sociales, los estereotipos y la subordinación por género; en definitiva, contra la función que el nacionalismo vasco les tenía reservada. De alguna manera, mediante su incorporación al universo patriarcal de la violencia con fines políticos, se busca una reafirmación como individuos y un reconocimiento como género perfectamente capaz de combatir en igualdad de condiciones con el género masculino. En boca de Yoyes: "Cómo lograr que mi presencia signifique de hecho que otras también puedan estar, [...] cómo lograr que estos hombres comprendan que la liberación de la mujer es un objetivo revolucionario para que lo asuman plenamente, [...]" (Katarain, 1987: 57).

\subsection{Representaciones de las mujeres de ETA en el propio discurso de la banda}

Las primeras evidencias escritas de la presencia de mujeres en la organización datan de 1963 -dos mujeres aparecen en la lista de participantes en la Segunda Asamblea -. La primera mujer en alcanzar el comité ejecutivo fue $\mathrm{M}^{\mathrm{a}}$ Dolores González Katarain (Yoyes), en 1978 (Hamilton, 2007).

A continuación, se retomará brevemente el conflicto entre feminidad y violencia, desarrollado en el primer apartado. La estructura patriarcal en torno a la cual se había constituido ETA, junto con sus reticencias a proporcionar un espacio al movimiento feminista nacionalista, tiene, lógicamente, una serie de consecuencias para las activistas femeninas -sobre todo para las que se incorporan durante la primera etapa, más o menos hasta mediados de los años 80, cuando la presencia de mujeres es muy reducida-. Aquéllas que aspiraban a involucrarse en la lucha armada debían realizar antes un sacrificio: renunciar a cualquier aspecto que pudiera remitir a su condición de mujeres, es decir, debían renunciar a su feminidad (Agra Romero, 2012). Como en cualquier otro sector del mundo real, las exigencias para poder pertenecer a la banda eran mayores para ellas que para ellos; tenían que escapar de un rol que la sociedad les había impuesto, y en ese momento la salida más cercana pasaba por convertirse en "no mujeres", adoptando una postura que actúa en detrimento de los valores femeninos y ayuda a perpetuar la subordinación por género de la que buscaban huir. Yoyes, primera mujer en alcanzar la cúpula, era plenamente consciente de este fenómeno: "hay un temor que 
últimamente me revuelve un poco, no quiero convertirme en la mujer que porque los hombres consideran de alguna forma macho, es aceptada"12 (Katarain, 1987: 57).

Sin embargo, no todas las consecuencias fueron negativas: abrieron el camino para la entrada de muchas otras mujeres a la organización, renunciaron al papel de salvaguardas de la pureza de la raza que el nacionalismo les había reservado y empezaron a construir una nueva feminidad, y comenzaron a deconstruir el género en lo respectivo al ejercicio de la violencia. Todo ello, a la vez que echaban por tierra las dos representaciones principales sobre ETA que operaban en el discurso dominante: la percepción general de que la actividad militar era exclusivamente masculina y de que el uso de la violencia por parte de sus miembros respondía a algún tipo de patología o enajenación con excesivas dosis de agresividad -tan impropias del género femenino-. En resumen, contribuyeron a la "despersonalización y a la politización" de la lucha de ETA (Hamilton, 2007).

\subsubsection{Representación de la maternidad en el discurso de ETA.}

La maternidad es un símbolo muy potente en la construcción de la identidad femenina, por lo que también va a influir en las concepciones y representaciones en torno a la aproximación de las mujeres a la violencia política: "The idea that motherhood determines women's views of, and participation in, armed actions has implications for our understanding of the wider gender politics of political violence ${ }^{13}$ (Hamilton, 2007: 119).

En los comienzos de la incorporación de las mujeres a la organización, entre las décadas de los 60 y los 80, las que fueron aceptadas tuvieron que renunciar a la maternidad, puesto que probablemente fuera uno de los símbolos más representativos de la feminidad por aquel entonces -al igual que tuvieron que renunciar a cualquier aspecto relacionado con su condición de seres "débiles"-. La primera etarra que consiguió convertirse en madre fue Yoyes, en 1982, teniendo este hecho unas implicaciones terribles para su vida, como estudiaremos más adelante.

Por aquel entonces -y no sólo por aquel entonces- el papel que ETA concedía a las mujeres era otro. El sistema de símbolos y representaciones operante en el nacionalismo radical vasco establecía un paralelismo entre los fallecimientos de los jóvenes que consagraban su vida a la lucha armada y la muerte de Jesucristo para redimir al mundo de sus pecados: ambos buscan la liberación de su pueblo. De modo que si el hijo se identifica con Jesucristo, la madre lo hace con la Virgen María; si el hijo es el héroe mártir que muere a manos del estado opresor español, la madre es amaberría [madre patria vasca], la que asume no sólo el dolor por la

\footnotetext{
${ }^{12}$ Cita recogida en Yoyes, desde su ventana, diaro que recoge la producción escrita de la vida de Yoyes. Refleja aquí sus inquietudes feministas, las contradicciones que le plantea su militancia en ETA, su periodo de duda, sus anhelos de ser madre y llevar una vida tranquila en Euskadi y hasta el miedo a una muerte inminente.

${ }^{13}$ La idea de que la maternidad determina la concepción de las mujeres de, y su participación en, acciones armadas tiene consecuencias para nuestro entendimiento general de las políticas de género de la violencia política (la traducción es nuestra).
} 
muerte de su hijo, si no el dolor de todo un pueblo. Luego la mujer tenía ya un papel muy acotado en la lucha por la liberación del pueblo vasco: "materializa la idea de continuidad y de mediación, el elemento purificador e integrador" (Agra Romero, 2012: 66). Era la encargada de transformar el funeral en un ritual político al constituirse en un auténtico nexo entre el pueblo y el mártir caído.

Si se analiza con detenimiento este modelo simbólico, se observa que convenientemente la figura del padre es apartada, como si no se quisiera dar lugar a ningún tipo de asociación entre el más mínimo atisbo de pasividad o debilidad y una figura masculina. Y también se observará que las únicas dos alternativas que tenía la mujer para encajar en este modelo eran o bien transformarse en "no-mujeres" y poder performar el papel de héroe mártir, o bien mimetizarse con el de madre mediadora y poner su vida al servicio de los demás (Agra Romero, 2012). De cualquier forma, se trata de un entramado de metáforas más que interesante y tremendamente influyente y referencial para el nacionalismo radical vasco, como se puede comprobar a lo largo de todo este ensayo.

Sus tentáculos han sido capaces de sortear las barreras del tiempo. Han encontrado apoyo, por ejemplo, en expertos que hoy en día aseguran la existencia de una relación entre la maternidad y la forma en que las mujeres abordan la violencia política. Es el caso de la socióloga Gilda Zwerman (1994), citado por Hamilton (2007), que, a pesar de posicionarse en contra del modelo de "pacifist mother [madre pacifista]" 14 , sí que defiende que las mujeres se sienten menos cómodas en roles activos como perpetradoras de violencia debido a su conexión con la maternidad.

Es necesario ser extremadamente cautos y cautas con este tipo de hipótesis, ya que, además de legitimar el modelo anterior, ofrecen soporte a concepciones y representaciones de las mujeres envueltas en la violencia política como torbellinos de frustración que no han podido cumplimentar su destino "natural" como madres, o a colocar sobre sus espaldas un nuevo crimen: el de renegar de su deber - otra vez "natural"- de ser madres. Por tanto, el efecto que puede producirse es que se vean invisibilizadas, como ya hemos visto, sus verdaderas motivaciones políticas.

\subsubsection{Análisis de dos acontecimientos representativos}

A continuación, por su gran poder ilustrativo, se analizarán dos hechos concretos que dan cuenta de los esfuerzos de las mujeres de ETA por hacer un hueco en la banda a un nuevo modelo de feminidad, implicado activamente en la lucha independentista y reticente a admitir una debilidad en sus valores que nunca fue tal. Se podrá percibir, asimismo, el extenso efecto siempre pernicioso- de las representaciones, imágenes, concepciones y asunciones desplegándose en torno a la mujer etarra, desde el ámbito mismo de la organización y del nacionalismo vasco.

\footnotetext{
${ }^{14}$ Modelo que defiende una relación especial entre las mujeres y la paz por su condición de madres.
} 


\subsubsection{Asesinato de Yoyes}

$\mathrm{M}^{\mathrm{a}}$ Dolores González Katarain -Yoyes-, primera mujer en alcanzar el comité ejecutivo de ETA, fue asesinada el miércoles 10 de septiembre de 1986 en Ordizia, su pueblo natal, en presencia de su hijo de tres años, siete años después de que decidiera abandonar la organización (Katarain, 1987). En el comunicado que lanzó la organización reivindicando su muerte, se le "acusaba de haber traicionado al Pueblo Vasco y de haberse traicionado a sí misma" (Agra Romero, 2012: 63).

En 1979, por discrepancias con la deriva militarista que toma ETA (m), decide abandonar su puesto en el comité y desvincularse de la banda. Se marcha a México, para regresar a España en 1985, acogiéndose a la amnistía política general decretada por el estado español en 1977. Aquí reside hasta ser ejecutada un año más tarde (Agra Romero, 2012). Tanto la prensa vasca como la española quisieron advertir en su muerte una especie de amenaza dirigida a posibles futuras disidencias, una enérgica protesta contra la política de reinserción individual. De hecho, en el mismo comunicado donde reclama la autoría de la muerte de Yoyes, ETA (m) (1986), citado por El Correo Español (12-09-1986), defiende que se trata de un instrumento para "crear fisuras en los sectores más vulnerables del Movimiento de Liberación Nacional Vasco con objeto de debilitarlo, ofreciendo una falsa e infame salida personal a aquéllos que se van traicionando a sí mismos". La cuestión es que Yoyes jamás se acogió a dicha reinserción, la ausencia de actividades delictivas a partir del decreto de la amnistía política general le permitió acogerse a la misma. Bajo ningún concepto existió nunca ningún tipo de colaboración entre Yoyes y el estado español. Sin embargo, cerca de 300 activistas sí que deciden acogerse a la oportunidad de una reinserción brindada por el gobierno “opresor" (Agra Romero, 2012).

Teniendo en mente toda la información relativa a su asesinato, se nos plantean dos grandes interrogantes: por qué su "traición" es peor o más peligrosa que la de cualquiera de sus excompañeros y por qué tiene lugar siete años después de su renuncia, y no en ese mismo momento. Se lanzarán posibles interpretaciones prestando especial atención al factor género, así como a las transgresiones efectuadas por la víctima y las consecuencias resultantes.

Ante todo, Yoyes era una mujer muy consciente de la idiosincrasia patriarcal de ETA. Como ya se ha visto, sabía que una militante tenía que realizar ciertos sacrificios en detrimento de su feminidad para ser respetada. Ella fue una de las primeras en procurar no acogerse a este modelo, como demuestran sus escritos; abogaba por una valoración justa de las facultades femeninas. Nunca aspiró a ser "un" gran etarra en el cuerpo de una simple mujer; por primera vez podría decirse que alguien aspiró a ser "una" gran etarra. Fue su primera gran transgresión.

También deconstruye el papel otorgado a la madre por el entramado ideológico abertzale. Fue la primera activista en convertirse en madre, proporcionando una base tangible a dos grandes rupturas con la simbología convencionalista del independentismo radical vasco: desafía la imposición tácita de ETA sobre las mujeres de renunciar a sus valores para poder entrar en la banda -no hay expresión más plena de feminidad que la maternidad-, y desaloja a la madre del nacionalismo vasco de su concepción como figura purificadora e integradora responsable de la 
continuidad y la mediación política. Una madre no podía ser también una heroína mártir, la madre se sitúa en otro plano; no desciende a labores tan terrenales, es un elemento estático cuya capacidad de resignación y sacrificio es casi mística. Simplificando, fue responsable de una confrontación insalvable con los convencionalismos sociales al situar a la madre en la esfera pública.

Pero además, el nacimiento del hijo de Yoyes también supuso la materialización de su salida de la organización, y la hizo visible al mundo. Una salida que ETA había decidido mantener en secreto, quizá con la esperanza de que algún día regresara. Aretxaga (2005), citado por Agra Romero (2012: 68), así lo expresa: “tener un hijo no era una mediación de continuidad política, sino llevar a cabo una ruptura irreversible con sus anteriores compañeros nacionalistas".

Haciendo un inciso, no se puede dejar de observar cierta actitud paternalista por parte de la organización sobre Yoyes. La decisión de no hacer público su abandono más bien parece una oportunidad para pensárselo mejor; como el padre consciente de que su hijo no ha tomado la decisión adecuada, pero aun así permite que la lleve a cabo y espera paciente a que vuelva a sus brazos con la lección aprendida. Bastante ilustrativa resulta también la acusación, plasmada en el comunicado posterior a su muerte, de haberse traicionado a sí misma. Se nos remite a la eterna minoría de edad de las mujeres y la necesidad de un tutor permanente.

Volviendo a las cuestiones que nos plantea el asesinato de $\mathrm{M}^{\mathrm{a}}$ Dolores González Katarain, nos centraremos ahora en el momento en que se produjo el mismo. Es evidente que Yoyes luchó abiertamente y en primera persona contra las diferenciaciones de género imperantes, pero su muerte fue perpetrada cuando hacía tiempo que había dejado de actuar en el escenario de ETA; la clave de su muerte quizás se sitúe en el tiempo elegido para regresar a España. Llegó en una época de disipación en la percepción social sobre los nacionalismos radicales vascos: ETA necesitaba, ante todo, unidad y una línea ideológica reconocible y clara. Unas diferenciaciones de género rígidas eran más que precisas para la mitologización del discurso hacia la que ETA estaba virando y para el afianzamiento de actos rituales -como los funerales o los homenajes a etarras fallecidos-, todo ello conducido a la unificación de la sociedad abertzale y la reconciliación entre militantes y simpatizantes (Agra Romero, 2012). Ella misma era consciente; el cinco de diciembre de 1985 escribía: "Hay claramente un receso hacia posturas reaccionarias, fanáticas, intolerantes, que dominan al resto de visiones, polarizando la situación, [...]” (Katarain, 1987: 208).

Pero no sólo contribuyeron a su muerte las diversas transgresiones de las diferenciaciones de género; precisamente el hecho de no ser una traidora la situó en un plano ambiguo que resultó ser crucial. No colaboró con el estado español, no se pasó al bando opuesto, simplemente aspiraba a ser independiente (Agra Romero, 2012). Esto iba totalmente en contra de la polarización de posturas que buscaba entonces la banda armada, necesaria para su continuidad. De manera que Yoyes no solo fue una transgresora en lo referente al género; se 
convirtió en una verdadera inclasificable, una transgresión "con patas", un elemento más que incómodo. En resumen, se convirtió en algo que convenía apartar del tablero.

Quizá sea necesario precisar que no se pretende defender la hipótesis simplista de que Yoyes fue asesinada por ser mujer, pero ¿hubiera sido ejecutada si hubiese sido un hombre?

\subsubsection{Funeral de Bakartxo Arzelus}

Ocho meses antes de la muerte de Yoyes, tiene lugar el primer funeral de una mujer militante en la historia de ETA -Miren Bakartxo Arzelus, abatida por la Guardia Civil el 15 de enero de 1986- (Agra Romero, 2012). Funeral que se convirtió en una batalla política entre la izquierda abertzale y el nacionalismo vasco conservador, adquiriendo tintes grotescos por la celebración sin disimulos de las relaciones de poder establecidas en base a la desigualdad de géneros, como se verá a continuación.

Procedamos, en primer lugar, al resumen de los acontecimientos. El padre de Miren, simpatizante del PNV -"ala derecha" del nacionalismo vasco-, quiso despedir a su hija en una ceremonia privada, prescindiendo de cualquier tipo de homenaje parte de la organización armada. Por su parte, el nacionalismo abertzale -“ala izquierda"-, escudándose tras la voluntad de la fallecida de prestar servicio a ETA, pretendió rendirle tributo como hubiera hecho con cualquier otro miembro de la banda, para lo que se llegó incluso a intentar secuestrar el cadáver.

Lo primero que llama la atención es que la figura de la madre desaparece para dejar hueco a la del padre. Es más, parece que quien se sitúa en un plano estático merecedor de algo más que las menudencias terrenales es la propia etarra, cediendo a su padre el papel activo y la autoría de lo realmente importante. Aun así, la izquierda abertzale se encargó de procurarle una madre "postiza" que encajara en su discurso: Itziar Airpurua -dirigente de $\mathrm{HB}^{15}$, una señora de 43 años, en aquel entonces, y sin hijos-. Una mujer que se acoplaba al papel requerido, por su edad y por su ideología, que se ocupó de darle la bienvenida en un acto simbólico al grupo de los héroes mártires que han dado la vida por su pueblo (Agra Romero, 2012). Se erigió en el recipiente del dolor por su muerte y en el agente mediador entre el hijo muerto y la sociedad vasca.

También resaltan en esta ocasión las altas dosis de paternalismo implícito en los hechos. ¿Por qué el padre no respeta la decisión de su hija de definirse políticamente en torno a la izquierda abertzale? ¿Por qué impone su significación política? Lo cual, una vez más, nos remite a la pregunta: ¿lo hubiera hecho también si en lugar de ser su hija hubiera sido su hijo?

Desde una perspectiva simbólica, podría afirmarse que estamos ante una imagen brutal del control ejercido sobre los cuerpos de las mujeres, del que no se liberan ni después de muertas. La mujer queda reducida de nuevo a un estatus correspondiente a poco más que un objeto, cuyo control se disputan uno y otro bando.

\footnotetext{
${ }^{15}$ Herri Batasuna: coalición política que aglutinaba a la izquierda abertzale.
} 
"Although she was hailed as ETA's first female martyr, the contest over Arzelus's corpse suggested that, unlike her male comrades, who in death were celebrated as Christ-like figures transcending earthly existence, the female activist would remain defined by her body. "16 (Hamilton, 2007: 166).

\section{Conclusiones y otros comentarios}

La sociedad vasca, como cualquier otra, reproduce el modelo patriarcal operante en su núcleo en todos los ámbitos, incluso en el del ejercicio de la violencia política.

Hoy en día, puede resultar más que interesante tener la posibilidad de aproximarse sin prejuicios al universo de dicha violencia - perpetrada por ETA-. En concreto, a la ejercida por las mujeres. Personas absolutamente normales, con unas motivaciones políticas fuertemente arraigadas y, probablemente, una concepción inamovible y casi mística de la lucha por la liberación del pueblo vasco - exactamente igual que sus homólogos masculinos-. Concepción, dicho sea de paso, promovida por el sistema de símbolos, representaciones y analogías que contribuye a la creación de la identidad nacionalista rebelde vasca. Un sistema que ellas mismas supieron superar y no permitir que les pasara por encima.

Es necesario reconocer el gran esfuerzo realizado por estas activistas, aunque la moralidad de sus actos sea más que cuestionable, por, en primer lugar, ser capaces de escapar del papel impuesto en su condición de mujeres por un nacionalismo tan identitario como el vasco y, posteriormente, ser capaces de abrirse un espacio en un mundo -el del ejercicio de la violencia con fines políticos- que directamente no contaba con ellas. Son artífices de una nueva identidad femenina vasca, que obviamente se ha intentado constreñir y adaptar a un imaginario compatible con la dictadura patriarcal.

$\mathrm{Y}$ es que todos los esfuerzos van dirigidos siempre a negar la capacidad de agencia de las mujeres y a perpetuar el control al que se las somete. Varían los medios, pero nunca el fin. Quizá, después de todo, el fin sí que justifique los medios (al menos con un fin tan conveniente).

En ningún momento a lo largo del presente estudio se ha pretendido justificar ninguna muerte ni restar brutalidad o dolor a ningún acto. Simplemente se ha puesto el foco sobre la parte objeto del mismo.

\footnotetext{
16 “Aunque ha sido aclamada como el primer mártir femenino de ETA, la disputa sobre el cadáver de Arzelus sugirió que, al contrario que sus camaradas masculinos, quienes son loados en su muerte como figuras similares a Cristo trascendiendo la existencia terrenal, la activista femenina permanecería definida por su cuerpo" (la traducción es nuestra).
} 


\section{BIBLIOGRAFÍA}

- Agra Romero, María Xosé (2012): “Con armas, como armas: la violencia de las mujeres". En: Isegoría, $\quad \mathrm{n}^{\mathrm{o}} \quad 46, \quad \mathrm{pp}$ : 49-74, [en línea] Disponible en: http://isegoria.revistas.csic.es/index.php/isegoria/article/view/773/772 [14/05/2015].

- Antolín, Matías (2004): Mujeres de ETA: piel de serpiente. Madrid: Temas de hoy.

- El Mundo (2009): "La dictadura del terror", [en línea] Disponible en: http://www.elmundo.es/eta/sociedad/ [14/05/2015]

- Hamilton, Carrie (2007): Women and ETA: The gender politics of radical Basque nationalism. Manchester University Press. [en línea] Disponible en: http://site.ebrary.com/lib/uamadrid/reader.action?docID=10623340 [10/05/2015]

- Hernández García, Jone Miren (1997): "Naciones, nacionalismos y ciudadanas, ¿de dónde?". En: Kobie. Antropología cultural, $\mathrm{n}^{\mathrm{o}}$ 8, pp: 19-26, [en línea] Disponible en: http://www.bizkaia.net/fitxategiak/04/ondarea/Kobie/PDF/5/Kobie_8_Antropologia_cultural NACIONES, $\% 20$ NACIONALISMOS $\% 20 \mathrm{Y} \% 20 \mathrm{CIUDADANAS}, \overline{\%} 20 \% \mathrm{C} 2 \% \mathrm{BF} \% \overline{20 \mathrm{DE}} \% 2 \overline{20 \mathrm{D}}$ ONDE_\%20.pdf [10/05/2015].

- Katarain, María Dolores González (1987): Yoyes desde su ventana. E. G. Lasa (ed.). Madrid: Alberdania.

- Zarzalejo, Charo (1982): "Hablan las mujeres de ETA”. En: Cambio 16, no 576, pp: 30-32.

- Zubiría, I. (1986): "Respetuoso silencio y miles de flores en el funeral por 'Yoyes' celebrado ayer en Ordizia". En: El Correo Español. El pueblo vasco, 12 de septiembre, [en línea] Disponible en: http://www.gesto.org/archivos/201312/8.-1986-prensa-yoyes.pdf?0 [13/05/2015]. 